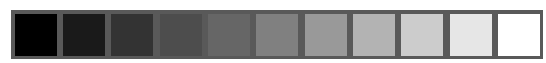

Imaginário - usp, 2007, vol. 13, n 14, 67-83

\author{
Os textos literários sobre Eva Perón. \\ Apropriações, representações e \\ deslocamentos do imaginário popular
}

\title{
Nidia Burgos*
}

La realidad que para el historiador es comprensible, para el escritor es recreable (Ernesto Goldar).

Es nuestra intención contribuir al debate crítico en torno a algunos textos que han ficcionalizado la vida, pasión y muerte de Eva Perón.

* Universidad Nacional del Sur Bahía Blanca, Argentina.

Nancy ARMSTRONG (1991), en su estudio sobre la novela de los siglos XVIII y XIX, parte de la convicción de que la ficción, es a la vez documento y principio motor de la historia cultural. Por ello, consideraremos la poética de algunas obras, puesto que en su trasfondo se evidencian las tensiones y problemas que el material histórico revela al narrador.

Nos parece indispensable realizar una nueva aproximación, dado que coexisten dos polos, uno que parte del análisis ideológico de múltiples textos, tal el caso de Ernesto GOLDAR (1971) quien publicó El peronismo en la literatura argentina, donde pasó revista a innumerables obras que aludían al peronismo desde junio de 1943 hasta 1970; y otro, que Ilanamente desconoce su mayoría, verbigracia el Tratamiento del peronismo en la literatura anglosajona, donde Mark Falcoff asevera: "no hay una sola novela en inglés sobre el peronismo. Lo que sí hay es la traducción inglesa de la novela de 


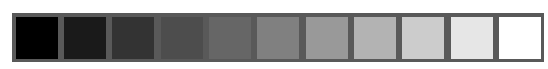

Burgos, N. Os textos literários sobre Eva Perón

1 En castellano recién se publicó en 1985 en Cerdos \& Peces, y en 1989 en la revista El porteño.
Beatriz Guido El incendio y las vísperas,[...]que yo sepa, es la única novela que trata el tema peronista" (FALCOFF, 1998, p. 5); cuando justamente, uno de los textos más urticantes, Evita vive en cada hotel organizado de Néstor Perlongher fue publicado por primera vez en inglés en $1983^{1}$.

Los textos que asediaron la figura de Eva Perón, en general establecieron una tradición de interpretación que repitió los lineamientos de una lógica cultural falocéntrica, que le otorga a la potencialidad femenina, causas patológicas. Marie Langer dice: "Por materializar viejas fantasías ejercía un poder mágico sobre todos. Sobre unos, como objeto externo a sus idealizaciones, y sobre otros, paralizándolos, por simbolizar para ellos el mal, la araña, la madre cruel que chupa, castra y mata" (LANGER, 1957, p. 94). En general, una escritura de hombres, que no puede asir el fenómeno del amor odio que despertaba Evita y que revela la imposibilidad de su representación, desde otro punto de vista, que el modo dicotómico del melodrama, por el cual, o es demonizada o canonizada. Nos intriga además, el especial atractivo que ejerce su figura, sobre ciertos escritores homosexuales, como Copi y Perlongher.

Eva dictó clases en La Escuela Superior Peronista y en ellas denotó un rechazo al pensamiento crítico. Incitaba a movilizar una fe ciega, un fanatismo absoluto, no en la doctrina que pretendía enseñar, sino en el líder que buscaba entronizar.

Yo no podría renegar jamás de mi fanatismo apasionado por la causa de Perón (PERÓN, 1987, p. 32). Perón, para mí, que lo he analizado profundamente, es perfecto (PERÓN, 1987, p. 140) [...] Decía Carlyle que "todos amamos a los grandes hombres, los amamos y nos prosternamos humildemente ante ellos, porque eso es lo que más dignamente humilla". Debemos humillarnos ante Perón, amándolo como conductor, como maestro y como autor de todas las glorias de nuestra historia del peronismo (PERÓN, 1987, p. 151).

En su discurso hay un afán de sometimiento al hombre que idolatra. Si bien por el fuerte liderazgo que adquirió sobre las masas 
y por el poder que de hecho tuvo, rompió los moldes que hasta entonces cercaban al género, paradójicamente fue la mujer que libremente accedió a someterse, a humillarse y prosternarse al hombre adorado. Tal vez por eso, su figura apasionó a los escritores homosexuales.

Su discurso nos recuerda el del homosexual que presentó Roberto Arlt en El juguete rabioso:

si yo pudiera daría toda mi plata para ser mujer... una mujercita pobre... y no me importaría quedarme preñada y lavar la ropa con tal que él me quisiera... y trabajara para mí. [...] Entonces todo su mísero cuerpo se deformara, pero "ella", gloriosa de aquel amor tan hondo, caminara entre las gentes y no las viera, viendo el semblante de aquel a quien sometíase tan sumisa (sic) (ARLT, 1981 , p. 81).

También en La brasa en la mano de Oscar Hermes Villordo hay un afán similar:

Y yo digo (me digo a mí mismo), doblado por tanto dolor, que daría mi vida para que todo volviera a suceder, para esperarlo, para repetir el nombre de Miguel, para oír su voz; para que el tiempo volviera, el mismo tiempo, cuando yo no sabía hacer otra cosa que amarlo (VILLORDO, 1983, p. 191).

Según Catherine Millot "la star y el ama de casa son los polos de identificación femenina de los transexuales" (MILLOT, 1984, p. 22).

Cuando Eva conoció a Perón, se entregó a un culto idolátrico, de una forma tan absoluta, que excede por lejos, la devoción de cualquier esposa convencional. Eva se enamoró del hombre, pero sobre todo, del programa político de Perón, de su plan de reivindicaciones a los postergados, por eso lo idolatra, porque ella fue la primera en ser elevada por él, convirtiéndose así en la "Abanderada de los Humildes".

De aquel modo, la mujer pública, según sus detractores, fue la más fiel. Y eso, ni ellos pudieron dudarlo: "Yo he dicho que Perón es mi luz, mi cielo, que es el aire, que es mi vida. Pero no solamente lo he 


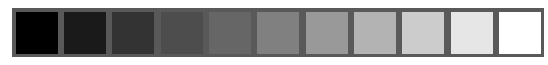

Burgos, N. Os textos literários sobre Eva Perón

dicho; he procedido como si así fuese. Por eso nadie puede dudar de que Perón sea para mí todo lo que afirmo" (PERÓN, 1987, p. 157).

Eva llegó a ser una metáfora de la Argentina. Recordemos que el film que inauguró la democracia, se denominó "La República perdida", como perdido estuvo también, el cadáver de Eva durante dieciocho años. El proyecto de erigir un monumento funerario, donde se exhibiese su cuerpo embalsamado sobre un cristal, para dar la sensación de que levitaba, se truncó con el golpe cívico-militar que destituyó a Perón en 1955. El cadáver fue retirado de la CGT con destino desconocido y ahí comenzó su interminable odisea. EI cuento Esa mujer de Rodolfo WALSH (1986) comenzado un día en 1961 y concluido en otro, de 1964, es el eje de la literatura de ficción de los años siguientes.

Autores como Tomás Eloy Martínez y Abel Posse comprendieron el imaginario peronista en su coherencia simbólica, tratándolo como un universo de significación autónoma. Así, Abel Posse se asume como un novelista que "ha sido más bien un coordinador de las versiones y peripecias que fueron delineando el mito" (POSSE, 1994, p. 11).

Cada autor, reelabora formas diversas y de algún modo subyacentes, en el imaginario popular sobre la vida y la muerte de Eva. Utilizan temas, símbolos y formas, entre ellas, la confesión autobiográfica, que a veces usan tanto el autor, como el narrador.

Muchos se ubican de lleno, en el ámbito de la ficción, lo que les permite colocarse sin contradicciones, en el interior mismo de la versión heredada del imaginario y simbolizar lo que ellos quieren ilustrar, en el marco de las polémicas ideológicas. Por ejemplo: Jorge Luis Borges, David Viñas, etc. Otros, desde el ensayo, pretenden alcanzar su comprensión a través de conceptos y categorías lógicas. Verbigracia: Eva Perón, ¿aventurera o militante? de Juan José Sebreli, quien a mediados de los 60 , objetivamente evalúa:

convertida en uno de los tabúes más inquietantes y peligrosos de nuestro folklore político, tiene la significación ambivalente de 
todo tabú; del sacer de los romanos, que significa sagrado, santificado, consagrado, y a la vez abyecto, execrable, impuro. Ella es la musa, la diosa madre y a la vez la mujer demonio, la mandrágora, la mantis religiosa (SEBRELI, 1966, p. 120-121).

Jorge Luis Borges en El simulacro, evoca con conmiseración, la reverencia con que el pueblo peronista erigió altares en todo el territorio, para homenajear a "la Difunta". Hubo un hecho real: los altares se erigieron en escuelas, lugares públicos y privados, pero Borges lo resemantiza al denominarlo y hacerlo funcionar en su ficción, no como un altar conmemorativo, sino directamente, como un simulacro del velatorio, en el que además, se hacía colecta a beneficio del viudo. Estos simulacros obedecían, según él, a la indisculpable ignorancia de sus seguidores.

Borges siempre insistió en interpretar los acontecimientos del periodo peronista como simulacros, en los que aparecía como un invariante, el aspecto dramático-sentimental. Verbigracia: "Más curioso fue el manejo político de los procedimientos políticos del drama o del melodrama. El día 17 de octubre de 1945 se simuló que un coronel había sido arrestado y secuestrado y que el pueblo de Buenos Aires lo rescataba .......]; con el tiempo fue creciendo el desdén por los prosaicos escrúpulos del realismo" (BORGES, 1955, p. 237-39).

Es fundamental la carga de significación, que le da a una escritura, el acercamiento a un hecho histórico. La ficción, en ese caso, es una metáfora de ciertas ideas, percepciones, sentimientos, emociones, que el narrador tiene sobre el mundo. Los autores han realizado apropiaciones y representaciones del imaginario popular y las han volcado en sus textos literarios. Encontramos en ellos, matices políticos implícitos o explícitos. La parodia del mito es, en general, la principal forma de apropiación, llegando a convertirse en un mecanismo productor de nuevos géneros.

Andrés Rivera dijo que "en la Argentina es difícil conocer a los personajes históricos por los historiadores, salvo, como se suele decir, honrosísimas excepciones" y Belgrano Rawson coincide en esto y lo explica así: 


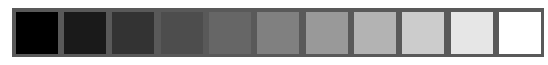

Burgos, N. Os textos literários sobre Eva Perón

biográficamente, las novelas no son exactas, pero las novelas van a lo esencial de los personajes, mucho más profundamente, más seductoramente que cualquier libro de historia. La seducción que nace alrededor de la figura asediada, la dimensión que adquiere, tiene mucho mayor eficacia que la que puede surgir del trabajo de un historiador (BELGRANO RAWSON, p. 48-49).

Joyce dijo "la historia es una pesadilla de la que estoy tratando de despertar", frase que Saer interpreta, como que el camino de la ficción, es salir de la historia, para dirigirse al mito (SAER, 1995, p. 78). Consideramos que éste, ha sido en general, el interés propulsor de estas historias en torno a Eva.

Todas las obras que la abordan, ofrecen diversas versiones del mito que ella encarna, que se sustentan, a su vez, en variadas visiones

2 Lamborghini (Buenos Aires, 1927) poeta y periodista. Vivió exiliado en México entre 1977 y 1990. En 1991 recibió el Premio Leopoldo Marechal y en 1996 el Boris Vian. Sus poemarios fundamentales son El saboteador arrepentido (1955), Las patas en la fuente (1965), Coplas al Che (1968), El solicitante descolocado (1971), Odiseo confinado (1992), Tragedias y parodias (1994), Comedietas (1995), Las reescrituras (1996), Carroña última forma (2001). del mundo, marcadas por la ideología.

Lamborghini (1972), en el poema Eva Perón en la hoguera, trabaja con la Eva idólatra. Toma diecisiete momentos o centros de significación de La razón de mi vida. Los núcleos de significación más importantes son: cuando ella se ve a si misma como un gorrión en la bandada y Perón es el cóndor que le enseña a volar. La revelación "los ricos como árboles, los pobres como pasto"; "el día maravilloso" cuando conoció a Perón; otro: "la incomprensión, los enemigos", cuando el 17 de octubre de 1945, fue reconocida y golpeada; y tuvo ahí su bautismo de fuego en la vida política y militante. Asumió entonces como deber la justicia social y tomó la bandera de los obreros peronistas.

Simon Weil, entre otros pensadores, ha manifestado la distancia insalvable entre la experiencia de la miseria y cómo expresarla. Por ello, en su periódico, reproducía testimonios y cartas de obreros, porque sólo ellos mismos, podían comunicar su situación. De igual modo, Lamborghini elige en el segmento IX mencionar las cartas que los pobres le dirigen a Evita: "las cartas: la elocuencia tremenda./ todas: del que necesita, cuanto antes cuanto antes,/ querida Evita./ las cartas: sus peticiones, del que necesita, la/ tremenda, la enorme, la cantidad: todos los días, las cartas:/ 
angustiosas Ilamados que son: querida Evita./ cuanto antes/ cuanto antes/".

Toma las audiencias en la Fundación y en aquella lucha, su defensa: "por eso afónica/ por eso: qué hacer/ por eso qué: cueste lo que cueste/ por eso qué: caiga quien caiga". Sus obras, y ella viéndose a sí misma como un pájaro libre, no encadenado al estado, ni a un cargo o función. En el penúltimo fragmento, repasa todos los núcleos mencionados y ya en el último, dice "Ya: lo que quise decir está./ [...]Ya: lo que quise, mi palabra está".

Lamborghini, al reelaborar el discurso de La razón de mi vida, que algún periodista escribió (¿Manuel Penella de Silva, Américo Barrio, o Albamonte?), para que lo firmara la Primera Dama, le otorga voz a Evita. Rescata la emoción pura, la efectividad sentimental de esta singular mujer, al exponer su figura en su conexión social.

Lamborghini al fragmentar La razón de mi vida, lo acerca al lector, lo exalta e ilumina, provocando una expansión semántica del mismo, y reubicando a Eva en el centro de ese discurso, en una notable tensión entre la consagración de un estereotipo y su renovación. Con su entrecortado acercamiento al texto-madre, muestra la complejidad del mito y al otorgarle a la literatura su especificidad fictiva, rompe la versión clásica de la ideología dominante: tanto la del peronismo triunfante en los 50, como la de la Revolución "Libertadora" posterior, en su intento de desmantelar los mitos.

Al fragmentar el texto adjudicado a Evita, lo desrealiza y lo convierte en un nuevo folletín. Hace de él, un sitio de tensión en el que se libran abiertamente las controversias del campo cultural, entre el sector intelectual al que Lamborghini y sus lectores pertenecen y el textomadre original, destinado a la cultura de masas.

En los textos de Néstor Perlongher ${ }^{3}$ y de $\mathrm{Copi}^{4}$ hay una fuerte violencia simbólica. Hay un uso provocativo de las posibilidades subversivas del imaginario lumpen, para socavar no sólo las jerarquías del mito, sino también, las de los géneros literarios con que abordaron el personaje. Las operaciones de carnavalización, subversión y perversión que ha realizado COPI (1970) en la obra de
3 Néstor Perlongher (Avellaneda, 1949 - Brasil 1992) poeta, ensayista, antropólogo, periodista, vivió en Brasil desde 1981 hasta su muerte Fue activo miembro del Frente de Liberación Homosexual y devoto de la religión del Santo Daime donde mezclaba droga, poesía, sexo y religión. Seguidor del barroco de José Lezama Lima, se 10 estima figura central del "neobarroso" rioplatense que desarrolló especialmente en sus cinco libros de poesía reunidos en Poemas Completos, Buenos Aires: Seix Barral, Biblioteca Breve, 1997.

4 Copi, Raúl Natalio Roque Damonte, hijo del periodista político Raúl Damonte Taborda y de China Botana, hija del conspicuo director del diario Crítica. Cuando murió su abuelo en 1941, comenzó una fuerte disputa familiar por el control del diario. La llegada de Perón al poder condujo a la familia al exilio. Así Copi se escolarizó en París. En 1955 la familia regresa a la Argentina arruinados económicamente. En 1962 regresa Copi a París. En 1968 participa del Mayo francés y en 1970 estrena Eva Perón bajo la dirección de Alfredo Arias. Recibe mala crítica, pero la pieza tuvo enorme éxito, Se gana la vida como dibujante de tiras de humor, escribe novelas en forma de folletín y también obras teatrales que dirigió José Lavelli. El 11 de diciembre de 1987 gana el premio de la Ville de Paris al mejor autor dramático y tres días después, muere de sida. 


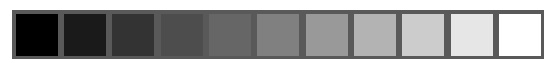

Burgos, N. Os textos literários sobre Eva Perón

teatro Eva Perón y Néstor PERLONGHER(1983) en el relato Eva vive en cada hotel organizado, en cierta medida las clarifica Leonidas Lamborghini, cuando dice que

\begin{abstract}
si se quiere expresar la carga trágica de nuestra realidad histórico política, lo eficaz es asimilar esa distorsión, asumirla y devolverla multiplicada. La verdad del modelo es su propia caricatura. Arte artero por lo que tiene de sarcástico e irónico. Por lo que tiene de ir a menos, en apariencia, cuando lo que se propone es apropiarse de la palabra del letrado, o más bien borrarla, para ubicar, en triunfo, a la palabra del marginado en el centro. Exploraciones de nuevas posibilidades de lo cómico, lo cómico como un límite desde el cual se expresa lo trágico. Lo cómico como lo verdaderamente trágico de nuestra situación, especie de risa desahuciada. La parodia como lo verdade-ramente serio. Relación burlesca con el modelo. Crisis de todos los modelos (LAMBORGHINI, 1995, p. 10-11).
\end{abstract}

Como oportunamente señalara BAJTIN (1974), lo carnavalesco expresa una cosmovisión deliberadamente opuesta a la oficial, pues invierte los valores imperantes, las jerarquías, (por caso, madre-hija en la obra de Copi), ocasionando su destrucción y regenerándolos a su vez, en una realidad opuesta: Evita vive de PERLONGHER, 2000, p. 157-166), en vez de padecer la enfermedad, la muerte, y el dolor por los pobres y afligidos, tal como la inmortalizó la ideología partidaria, goza desvergonzadamente de su cuerpo y procura también placer carnal a otros.

Sabemos que el cuerpo y sus excesos: comida, sexo y violencia, son la marca de lo carnavalesco, y muerte y resurrección son sus variantes fundamentales. A propósito, cabe señalar que el peronismo, desde que surgió como movimiento, fue considerado carnavalesco y muchos textos literarios lo relacionaron también al libertinaje sexual. Así Elvira Orphée en la novela Uno, describía:

En la plaza hay una comunidad de caras oscuras[...]la promiscuidad se enseñorea en la plaza. De pronto, como conjuradas, aparecen en algunas manos cacerolas viejas; el ritmo de sus golpes resucita tambores de brujo. Es la selva podrida, sexual, 
acumulada, que da una furia de crecimiento y un miedo a que la muerte en acecho salte encima antes de que el sexo se cumpla. [...] Antes las maternidades se llenaban en setiembre, el tiempo justo después de Carnaval. Entonces decían que el padre era un Pierrot, ahora dirán que es un ferroviario o un textil (citado por GOLDAR, 1971, p. 74-75).

Las fiestas peronistas, el 17 de octubre, por ejemplo, se celebraban siempre en la plaza pública y a veces la violencia se manifestó en ellas, especialmente incitada por los discursos de los líderes y las acciones de algunos grupos. De ahí que por entonces, el accionar de la masa peronista, fuese visto como una amenaza por las otras clases sociales, o por los disidentes del peronismo. BIOY CASARES y BORGES (1947) dieron cuenta de aquel aspecto en el cuento $L a$ fiesta del monstruo.

Néstor Perlongher a su vez, le ha dedicado a Evita dos poemas: El cadáver y El cadáver de la Nación (4 partes). En ellos repasa el proceso de embalsamamiento y amortajamiento de la difunta, deteniéndose en detalles concernientes a lo estético, desde la voz de sus agentes: el peluquero, la manicura o el embalsamador.

Dado que el Dr. Pedro Ara, tuvo una obsesiva preocupación por lo estético, logró despojar a Eva de los atributos de la muerte: rigidez, olor nauseabundo, opacidad de la piel, etc, a tal punto, que se rumoreó que el cadáver no era tal, sino una representación de ella. Y esto, trajo a su vez, una consecuencia no deseada:

Este trastocamiento entre el verdadero cuerpo y sus representaciones termina afectando al cadáver mismo, al que se acabará tomando como una muñeca, [de este aspecto se ocuparon "El simulacro" de Borges y Santa Evita de Tomás Eloy Martínez] Si se toma al cuerpo como muñeca, como representación de Evita y no como Evita muerta, todo el emprendimiento se vacía de sentido (CORTÉS R.; KOHAN, 1998, p. 72).

Este sin sentido que acabaron cobrando los ritos, sumado a la falta de resolución, por parte de los militares que desalojaron a Perón del poder, sobre qué destino darle al cadáver, cuyo aspecto de 


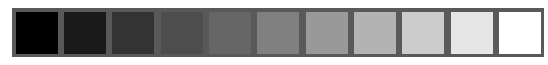

Burgos, N. Os textos literários sobre Eva Perón

serena placidez, inducía a pensar que dormía, extendió la sensación de sin sentido al país todo. Su cadáver se convierte en "el cadáver de la Nación", y entonces ella, "auténtica, desmesurada, obvia casi, se ofrece sin concesiones a la literatura" como señala Goldar (1971, p. 63).

El hecho de que multitudes participaran de los ritos funerarios, unido a las pompas que se le dispensaron: música sacra en las radios durante días, luto obligatorio a todos los empleados públicos, convirtieron su muerte en una marca indeleble del imaginario colectivo.

Dice Claudia Soria que las preguntas sobre quién es Eva "caen en un agujero interpretativo que escapa al lenguaje, al orden simbólico [...] por ello no es caprichoso que la muerte de Eva no se anuncie como el fin de la vida sino como el comienzo de otra..." (SORIA, 2005, p. 155).

Néstor Perlongher en su relato Evita Vivenarra el retorno de Eva: "era ella nomás, inconfundible, con esa piel brillosa y las manchitas del cáncer por abajo, que - la verdad - no le quedaban nada mal" (PERLONGHER, 2000, p. 160).

La historia de Perlongher parece continuar el derrotero de aquella Evita que escapó de la obra teatral de Copi. Eva regresa y con escatológica desmesura, el autor la muestra realizando "un intercambio crapuloso con el lumpenaje [...] en un deseo de absorber el cuerpo lumpen. El lumpen como motor y como renovación de las

5 Esta expresión, Jorge Panessi no la utiliza para Evita vive, pero nos parece aplicable a este texto. Cfr. "Detritus" en Lúmpenes peregrinaciones. Ensayos sobre Néstor Perlongher, Rosario, Beatriz Viterbo Editora, 1996, p. 48. relaciones" dice Jorge Panessi ${ }^{5}$, quien también observa el "frote lingüístico de la germanía", aplicable asimismo al texto que nos ocupa. Como bien dice Christian Ferrer: "para Néstor Perlongher, ella fue, ante todo, lumpen" (FERRER, 1996, 186) Pero ella no era lumpen, de ningún modo. A Eva y a su familia les interesó encuadrarse permanentemente en los valores burgueses. De humildísimo origen, pero con aspiraciones y sueños pequeño burgueses que la emparentan con el personaje de Silvio Astier en El juguete rabioso; en el hogar en que creció, se soñaba con una instrucción, con estudios, libros, y hasta lujos. Todas los hijos de Juana Ibarguren alcanzaron la escolaridad obligatoria y además Blanca fue maestra, (en los años 30, era un título ambicionado en la clase media), la otra 
hermana, Elisa, oficinista. Ambas se casaron "bien", una con un abogado, otra con un militar. Ambos cuñados habían sido pensionistas de su madre. $Y$ esa constituye, entonces, la gran apropiación que hacen Copi y Perlongher, arrebatarla para el lumpen, el abajo, el detritus de lo marginal. Por eso, en los relatos de Evita vive, ella vuelve para, "con maneras de princesa ordinaria", reinar en la marginalidad de los bajos fondos, mezcla de zona roja y villa miseria, donde protagoniza sexo promiscuo y consume drogas con personajes lúmpenes y se defiende con prepotencia de la policía, aludiendo con procacidad a su pasado de "hada buena". Así, se transforman absolutamente los mitos que fueron forjados por el aparato partidario, para resistir su poder. En el microespacio del texto, Perlongher con tremendos rituales escatológicos, participa activamente en la destrucción del mito, refutando los valores construidos por la mitología justicialista ${ }^{6}$.

Tal vez, la clave de la escritura de Copi y Perlongher, esté en lo que dice Tomás Eloy Martínez "Todo lo que el cuento decía [Esa mujer de Rodolfo Walsh] era verdadero, pero había sido publicado como ficción y los lectores queríamos creer también que era ficción. Pensábamos que ningún desvarío de la realidad podía tener cabida en la Argentina, que se vanagloriaba de ser cartesiana y europea" (MARTÍNEZ, 1995, p. 304) [El señalado es nuestro]. Copi y Perlongher entonces, en aquel reino del sin sentido en que se convirtió la Nación, utilizan estrategias de subversión, herejía y heterodoxia, manifestando así su disconformidad con el tono que adoptaron las prácticas de escritura normalmente admitidas sobre el mito. Por ello, describen rituales perversos en los que, a través de sus juegos y tretas, desbaratan la coherencia de los mitos sobre Eva que organizó la liturgia peronista.

Copi, Perlongher y Lamborghini, parten de considerar que una dominación social instituyó los mitos, convirtiéndolos en frutos de una cultura dominada. Desde ese lugar, interpretan sus producciones simbólicas.

Si para las masas peronistas, la enfermedad con su martirio, había espiritualizado la carne de Eva, hasta elevarla a la santidad, Copi,

6 La mitología peronista se caracteriza por una fuerte simbología que se denota en sus emblemas: el escudo y la marcha peronista, la figura del descamisado, las fechas de nacimiento de Perón y de Eva, la del día y la hora de "su paso a la inmortalidad".

El 31 de agosto, cuando ella declina el ofrecimiento de acompañar la fórmula presidencial como vicepresidenta, se lo denomina Día del Renunciamiento. El 18 de octubre de 1952 se declara día de Santa Evita y el día ante-rior, Perón la llamó "estandarte de nuestro movimiento y una de las más grandes mujeres de la humanidad". El 24 de enero de 1952, el Congreso en sesión extraordinaria, acuerda otorgarle el título de Jefa Espiritual de la Nación. El 26 de junio, el Congreso acuerda erigirle un monumento, con réplica en todas las capitales de provincia. En julio, en todos los templos del país, se reza por su recuperación. Cuando fallece, su cuerpo es embal-samado y luego exhibi-do en el ministerio de Trabajo y Previsión. El 1 de agosto, el féretro es llevado en una cureña tirada por 42 sindicalis-tas, primero al Congreso y de ahí, a la CGT, donde se le erigiría una pirámide de cristal, que protegería su cuerpo para la eternidad. Al cumplirse un mes de su fallecimiento, se realizó una procesión de antorchas, encabezada por el propio Perón. Y ya muerta, los pobres siguieron enviando cartas "A Evita que hace el Bien". 


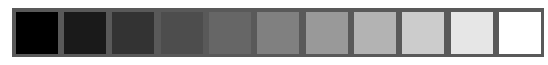

Burgos, N. Os textos literários sobre Eva Perón

7 En la obra de Copi, Evita misma reemplaza las ampollas de medicamento y asesina a la enfermera, para que ésta, la sustituya en el féretro, mientras ella escapa por su parte, se permite entender su enfermedad como una farsa y su muerte como un simulacro ${ }^{7}$, tal como la interpretó Borges.

Eva Perón de Copi se caracteriza por una recreación carnavalesca y macabra de la figura de Evita y de su entorno. Porque como bien dice Roberto Echavarren: "Eva Perón es una bandera efectiva y grotesca que enarbolan las minorías que devienen mujer. Devenir, según lo entienden Deleuze y Guattari en Mil planicies, no una hembra real, o biológica, y menos aún un disfraz, un travesti, sino intensidades-mujer, contaminaciones cruzadas, pastiches-mujer; no menos reales" (ECHAVARREN, 1996, p. 118).

Copi y Perlongher, hacen converger en Eva el cruce de las oposiciones santa-prostituta. Construyen una categoría anómala, utilizando las valoraciones maniqueas que se le otorgaron a su imagen, jugando con ellas. Manipulando valoraciones que no los satisfacen, cambian los significados que entronizaban los mitos erigidos, resistiendo su poder.

¿De qué sirvió que particularmente Copi y Perlongher, produjeran esta verdadera implosión del mito? Que tal vez, a partir de ahí, a juzgar por la reciente novela de Carlos GAMERRO (2004), La aventura de los bustos de Eva, aparentemente los autores han quedado liberados, tanto de la mitología justicialista, como de la celebración escatológica, para, en el icono simbólico de la "Abanderada de los humildes", poder mirar el pasado reciente, las confusiones ideológicas, la intolerancia y aún la muerte, con la posibilidad de hacerlo como Gamerro, desde la ironía, que es una forma de la sabiduría, desde el abierto humor y la restauradora carcajada.

Resumo: Os textos publicados em torno à figura de Eva Perón, de forma geral, estabeleceram uma tradição que seguiu os delineamentos de uma lógica cultural falocêntrica, que confere causas patológicas à potencialidade feminina. Em geral, uma escrita de homens, que não consegue apreender o fenômeno de amor/ódio que despertava Evita, obrigando-os a representá-la demonizada ou canonizada. 
Os autores realizaram apropriações e representações do imaginário popular e as aplicaram em seus textos literários. Todas as obras que se referem à Eva Perón, oferecem diversas versões do mito que encarna, que se sustentam, por sua vez, em diversas visões do mundo, marcadas pela ideologia.

Intriga-nos também, o especial atrativo que sua figura exerce sobre certos escritores homossexuais, como Copi e Perlongher. Eles fazem convergir em Eva o cruzamento das oposições santa-prostituta. Constroem uma categoria anômala, utilizando e jogando com as valorações maniqueístas que atribuíram a sua imagem. Manipulando valorações que não os satisfazem, mudam os significados que entronavam mitos erigidos, resistindo a seu poder.

Concluímos que após diversas abordagens, aparentemente os autores foram liberados, tanto da mitologia justicialista, quanto da celebração escatológica.

Palavras-chave: Eva Perón, apropriações, representações, deslocamentos, imaginário popular, mito, textos literários.

\begin{abstract}
In general terms, texts concerned with Eva Perón's figure have established a tradition that repeated the lineaments of a phallic-centered cultural logic, which grants pathological sources to feminine potentiality. Most of male writers cannot grasp the love-hate phenomenon inspired by Evita; it has compelled them to represent her in a sanctified or a devilish portrait.
\end{abstract}

Authors have made appropriations and representations of popular imagery and transferred them into their literary texts. Every work that approaches Evita offers diverse versions of the myth that she incarnates and that are supported, in their turn, by diverse visions of the world, framed by ideology. 


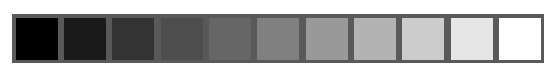

Burgos, N. Os textos literários sobre Eva Perón

Besides, we are intrigued by the special attraction that her figure exerts on some homosexual writers, like Copi and Perlongher. They make converge in Eva the junction of saintprostitute oppositions. They build an anomalous category, using Manichean assessments that have been brought to her image and playing with them. By manipulating assessments that do not satisfy them, they change meanings that enthroned established myths, resisting their power.

Finally, we conclude that, after these diverse representations, the authors have been apparently released both from the justicialistic mythology and the scatological celebration.

Key words: Eva Perón, appropriations, representations, displacements, popular imagery, myth, literary texts.

Resumen: Los textos que asediaron la figura de Eva Perón, en general establecieron una tradición que repitió los lineamientos de una lógica cultural falocéntrica, que le otorga a la potencialidad femenina, causas patológicas. En general, una escritura de hombres, que no puede asir el fenómeno del amor odio que despertaba Evita, lo que los obliga a repre-sentarla demonizada o canonizada.

Los autores han realizado apropiaciones y representaciones del imaginario popular y las han volcado en sus textos literarios. Todas las obras que la abordan, ofrecen diversas versiones del mito que ella encarna, que se sustentan, a su vez, en variadas visiones del mundo, marcadas por la ideología.

Nos intriga además, el especial atractivo que ejerce su figura, sobre ciertos escritores homosexuales, como Copi y Perlongher. Ellos hacen converger en Eva el cruce de las oposiciones santa-prostituta. Construyen una categoría anómala, utilizando las valoraciones maniqueas que se le otorgaron a su imagen, jugando con ellas. Manipulando valoraciones que 
no los satisfacen, cambian los significados que entronizaban los mitos erigidos, resistiendo su poder.

Concluimos en que después de estos variados tratamientos, aparentemente los autores han quedado liberados, tanto de la mitología justicialista, como de la celebración escatológica.

Palabras clave: Eva Perón, apropiaciones, representaciones, desplazamientos, imaginario popular, mito, textos literarios.

ARMSTRONG, N. Deseo y ficción doméstica. Una historia política de la novela. Madrid: Ediciones Cátedra, 1991.

ARA, P. Eva Perón. La verdadera historia contada por el médico que preservó su cuerpo. Buenos Aires, Editorial Sudamericana, 1996.

ARLT, R. El juguete rabioso. En: Obra Completa, tomo I, Buenos Aires: Ediciones Omeba, 1981.

BAJTIN, M. La cultura popular en la Edad Media y en el Renacimiento. El contexto de François Rabelais. Barcelona: Barral Editores, 1974.

BIOY CASARES, A.; BORGES, J. L. La fiesta del monstruo. En: Perón Vuelve. Cuentos sobre peronismo. Selección de Sergio S. Olguín. Prólogo de Jorge Lafforgue. Buenos Aires: Grupo Editorial Norma, 2000, p.41-59.

BORGES, J. L. L'illusion comique. En: Sur, (237), Buenos Aires, novdic. 1955 , p. 9-10.

. El simulacro. El Hacedor. En: Obras Completas, Buenos Aires: Emecé Editores, 1974, p.789.

COPI. E. P. Traducción de Jorge Monteleone, Buenos Aires: Adriana Hidalgo editora S.A., 2000.

CORTÉS ROCCA, P.; KOHAN, M. Imágenes de vida, relatos de muerte. Eva Perón: cuerpo y política, Rosario: Beatriz Viterbo Editora, 1998. 


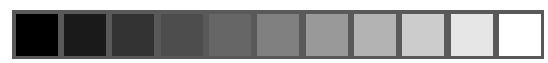

Burgos, N. Os textos literários sobre Eva Perón

DELEUZE, G.; GUATTARI, F. Mil mesetas. Capitalismo y esquizofrenia, Buenos Aires: Pretextos, 1988

ECHAVARREN, R. Un fervor neobarroco. En: Lúmpenes Peregrinaciones. Ensayos sobre Néstor Perlongher. Adrián Cangi-Paula Siganevich Compiladores, Rosario: Beatriz Viterbo Editora, 1996, p.115-123.

FALCOFF, M. Tratamiento del peronismo en la literatura anglosajona. Buenos Aires, Instituto Nacional Juan Domingo Perón de Estudios e Investigaciones Históricas, Sociales y Políticas, 1998.

FERRER, C. Escamas de un ensayista. En: Lúmpenes Peregrinaciones. Ensayos sobre Néstor Perlongher. Adrián Cangi-Paula Siganevich Compiladores. Rosario: Beatriz Viterbo Editora, 1996, p. 181-93.

GAMERRO, C. La aventura de los bustos de Eva. Buenos Aires: Editorial Norma, 2004.

GOLDAR, E. El peronismo en la literatura argentina. Buenos Aires: Editorial Freeland, 1971.

LAMBORGHINI, L. Eva perón en la hoguera. En: Proun, Bahía Blanca: Año I, Número I, Primavera 1997, p.33-40. (Primera edición, Buenos Aires: Corregidor, 1972).

LAMBORGHINI, L; RIVERA, A; BELGRANO, R. E; SAER, J. J; CONTI, J; RUSSO, M. La Historia y la Política en la ficción argentina. Santa Fe, Argentina: Centro de Publicaciones, Universidad Nacional del Litoral, 1995.

LANGER, M. Fantasías eternas a la luz del Psicoanálisis, Buenos Aires, Editorial Nova, 1957.

MARTÍNEZ, T. E. Santa Evita. Buenos Aires, Editorial Planeta Argentina S.A., 1998. (Primera edición 1995).

MILLOT, C. Exsexo: ensayo sobre el transexualismo, traducción de Cristina Davie, Buenos Aires: Editorial Catálogos, 1984.

PANESI, J. Detritus. En: Lúmpenes Peregrinaciones. Ensayos sobre Néstor Perlongher. Adrián Cangi-Paula Siganevich Compiladores. Rosario: Beatriz Viterbo Editora, 1996, p. 44-61.

PERLONGHER, N. Poemas Completos (1980-1992), Edición y prólogo Roberto Echavarren, Buenos Aires: Seix Barral, Biblioteca Breve, 1997. 
Evita vive. En: Perón Vuelve. Cuentos sobre peronismo. Selección de Sergio S. Olguín. Prólogo de Jorge Lafforgue, Buenos Aires: Grupo Editorial Norma, 2000, p. 157-66.

PERÓN, E. Historia del Peronismo. Buenos Aires: Editorial Volver, 1987. [1ra edición 1951].

. La razón de mi vida, Buenos Aires: Editorial Peuser, 1951. POSSE, Abel. La pasión según Eva, Buenos Aires: Emecé Editores, 1994.

SEBRELI, J. J. Eva Perón, ¿aventurera o militante? Buenos Aires: Ediciones Siglo XX, 1966, 2da edición.

SORIA, C. Los cuerpos de Eva. Anatomía del deseo femenino, Rosario, Beatriz Viterbo Editora, 2005.

VILLORDO, O. H. La brasa en la mano, Buenos Aires: Editorial Brughera, 1983.

VIÑAS, D. La Señora muerta. En: Perón Vuelve. Cuentos sobre peronismo. Selección de Sergio S. Olguín. Prólogo de Jorge Lafforgue, Buenos Aires: Grupo Editorial Norma, 2000, p. 61-72.

WALSH, R. Esa mujer. En: Los oficios terrestres. Buenos Aires: Editorial de la Flor, 1986, p. 7-19.

e-mail: nburgoscasal@speedy.com.ar

Recebido em 18/07/2006.

Aceito em 20/09/2006. 


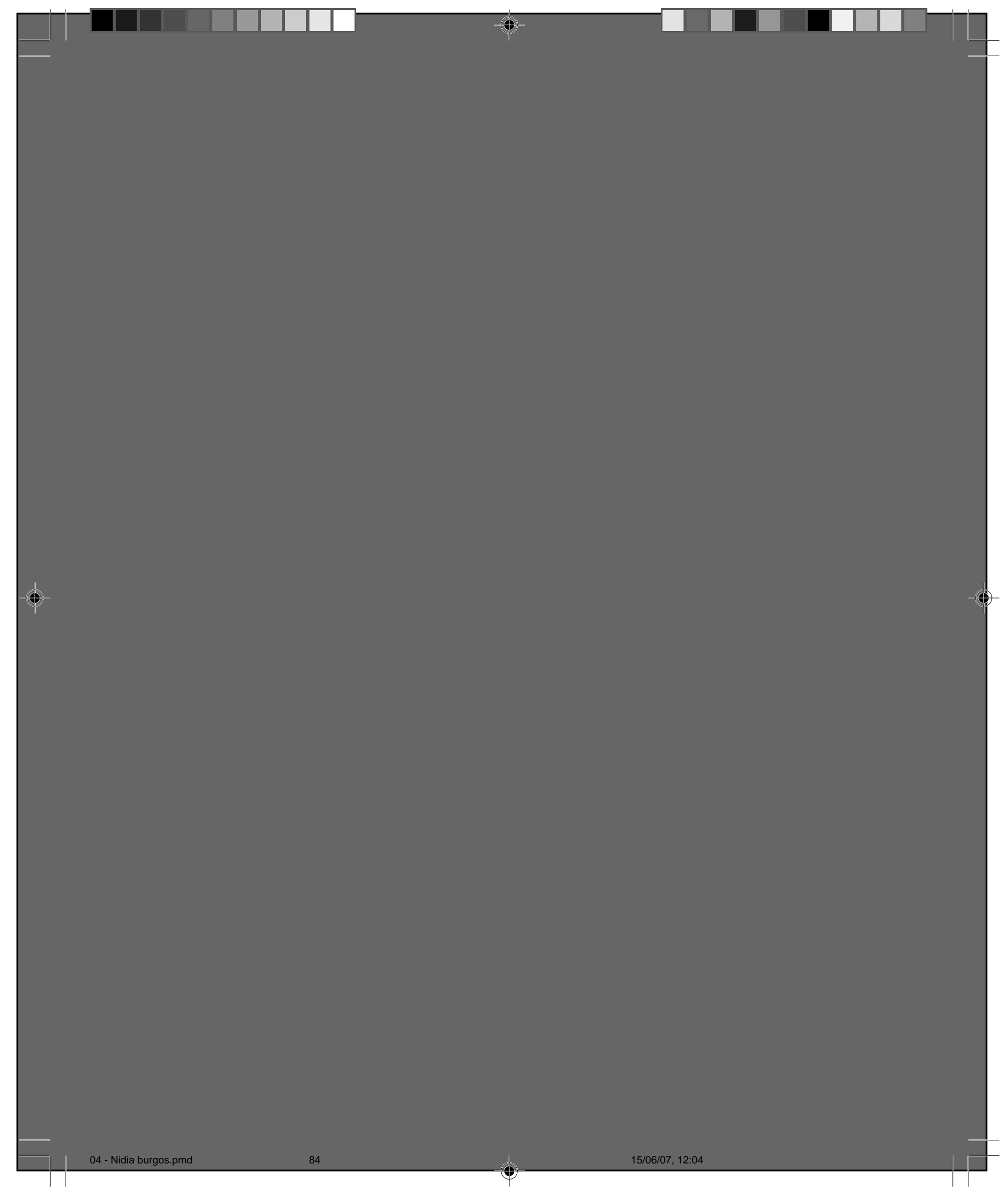

